\title{
Heating Water and Tap Water Production with an Air-to-Water Heat Pump by Using the Waste Heat of an Oil-Free Air Compressor
}

\author{
Cem Gulseven ${ }^{1}$, M. Zeki Yilmazoglu ${ }^{1,2, *}$ \\ ${ }^{1}$ Gazi University, Faculty of Engineering, Department of Mechanical Engineering, Ankara, Turkey \\ ${ }^{2}$ Gazi University Hospital, Technical Department, Ankara, Turkey
}

\begin{abstract}
Existing buildings require optimization of the individual heating systems to decrease the energy consumption or energy use intensity (EUI) with heat recovery systems to maintain the sustainability. In terms of energy use intensity, hospitals are considered as the second highest EUI among diverse types of buildings. Therefore, to decrease energy use intensity in hospitals heat recovery options have to be analysed. In this application, oil-free air compressors' waste heat is recovered by using air-to-water heat pumps for providing hot tap water (around 10\% of total) during summer mode and heating water for radiators placed in an emergency waiting room ( $42 \mathrm{~m}^{2}$ area) during winter mode at Gazi University Hospital, in Turkey. The results showed that previously the unserviceable area get in use with a PMV value of +1 . The payback period for the implemented system is found to be 2-4 years depending on heat load variations.
\end{abstract}

\section{Introduction}

The basic necessities of humanity such as energy, education, security, and healthcare are progressively growing and energy consumption related to these needs are also growing in demand as parallel with increasing population [1].

The need for healthcare facilities is growing by urbanization and increasing amount of diseases through the future. This will lead more energy consumption required to treat the troubles of humans facing on their health. Healthcare buildings are getting larger, most likely to meet the needs of the population whose average life expectancy continues to increase [2].

Electricity consumption of healthcare facilities by end-use is 248 trillion Btu according to the report of EIA, in 2003 Commercial Buildings Energy Consumption Survey [3]. Hospitals are consuming significantly higher energy with enormous energy intensity when compared to other commercial buildings such as offices and educational facilities. According to Commercial and Institutional Consumption of Energy Survey Summary Report, hospitals are the second largest activity sector by total energy intensity in Canada [4].

European Union have created an energy roadmap designed for 2050 which aims reducing greenhouse gas emissions by $80-90 \%$, when compared to 1990 levels, in manners of a greener future by counteracting the negative outcomes of the climate change. In this long-term energy strategy, enhanced energy efficiency and remarkable use of renewable energy sources hold significant function for obtaining sustainable energy systems and European citizens can access secure, affordable and sustainable energy source, accordingly [5]. This leads to a call for reevaluation of constructed HVAC systems for optimization and revision, which are in use as commercial, residential and industrial buildings.

Inpatient healthcare buildings are the most intensive users of water among large commercial buildings. Inpatient healthcare buildings constructed before 1960 used 55 gallons per square foot compared to 45 gallons per square in buildings constructed in 2000 or later which is a statistically significant difference between other commercial buildings in USA [6]. As hot water supply is essential for hygiene and medical operations, it is also needed for space heating. Hospitals are in the third place in terms of average square feet per building energy consumption, mostly from HVAC applications to heat spaces [2]. These HVAC applications also include the air supply for healthcare operations.

Many commercial and industrial buildings have varying types of heating plants consisting heat pumps, boilers, gas and oil fired heaters [7]. Using a heat pump to recover and recycle exhaust heat in a heating plant has considerable impacts on efficient consumption of energy. In addition, heat pumps have an increasing trend in heating and cooling applications, using a variety of sources such as ground, geothermal, water, air, and solar. The heat pump technology is developing over years, and many kinds of heat pumps are in use for various applications [8-9].

In literature, it is possible to find several research studies, which utilize heat pumps to decrease the energy

M. Zeki Y1lmazoglu: zekiyilmazoglu@gazi.edu.tr 
use intensity. These studies are mainly vary and diverse by the waste heat source as wastewater that heat pumps are using such as urban sewage water, domestic waste waters, raw water, and seawater. Nam et al., numerically simulated a groundwater heat pump drawing water from a well or surface water to a heat exchanger and discharge water into an injection well or a river as an example of open-loop system [10]. Liu et al., enhanced a heat pump system used in public shower facilities for exhaust heat recovery [11]. De Pasquale et al., investigated the integration of a district heating heat pump for heat production with the drinking water network where it is playing a role of low temperature heat source, as an alternative to fossil fuel heating [12]. Cipolla et al., analysed the possibility of using sewer water placing a less valuable heat source than fossil fuels, where its heat can be recovered by using heat pumps and heat exchangers [13].

The presented heat recovery operation in this work is obtained from oil-free air compressors waste heat by using air-to-water heat pumps $(2 \times 16 \mathrm{~kW})$ to produce heating water for emergency waiting room in winter. In addition, this system provides hot water for use in summer time to a block, belonging to hospital that is consisted of 60 inpatient rooms. This application examines the possibility of using the heat pumps in each season to decrease the payback time.

\section{Application}

Pressurized medical air is used in several essential locations including clean rooms and operation theatres in hospitals and it is desired to maintain the medical air with least particles, such as vaporized oil, and humidity. In addition, medical air is required for the safe operation of the medical devices with minimum contaminants. Pressurized medical air with a pressure of 9-10 bar is produced by the compressors and used in different areas requiring different pressure levels; pressurized air at 7 bar for general purposes, and at 4 bar for operating rooms and critical care units. Oil-air compressors are the type that is generally chosen to supply the medical air. However, parallel to the improvements in health standards, Gazi University Hospital upgraded its pressurized air system to oil-free compressors (Fig. 1) to minimize contaminants. Another important criterion in taking this decision is the failure of biomedical devices caused by oil particle accumulation on the electronic cards. It was a confirmation that the separator and chemical dryers were not functioning properly. As a result, whole system including compressors, vacuum, and medical gas was upgraded (Fig. 3).

The operation of oil-air compressors causes a little amount of oil vapour leakage in the air and bypass through the separators during the air compression process. In contrast to this, oil-free compressors use softened water to compress the air and prevents oil leakage accordingly. Additionally, chemical drying system has dew point temperature around $-61^{\circ} \mathrm{C}$ that

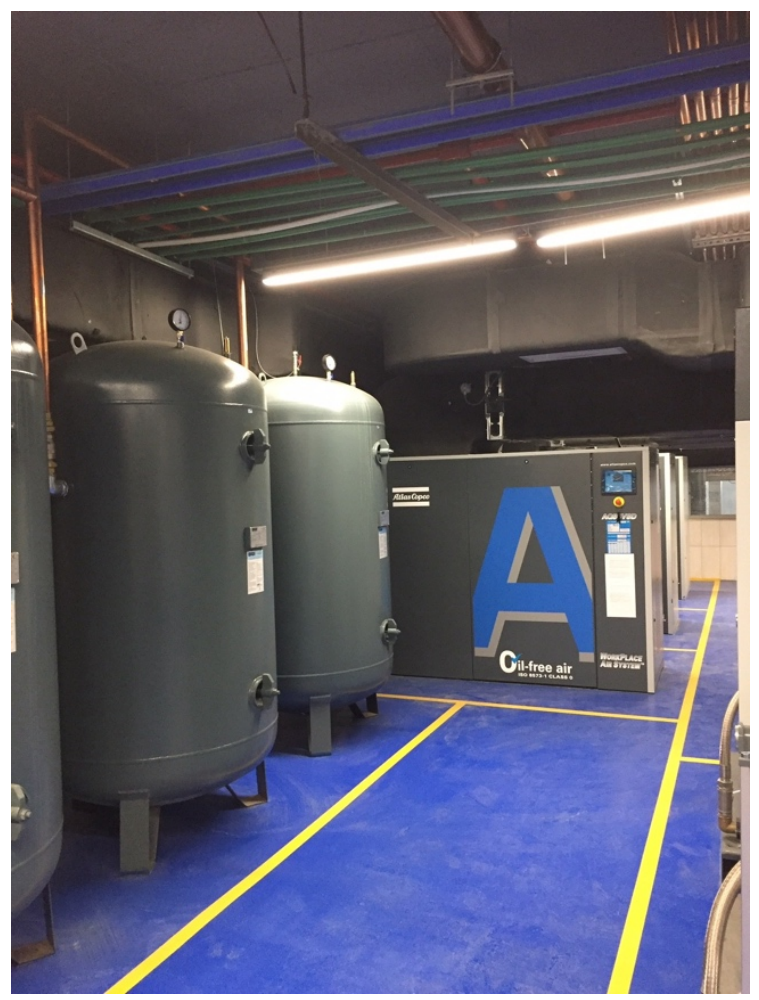

Fig. 1. Location of Oil-Free Air Compressors (center) and Air Tanks (left).

eliminates all particles in the medical air. In terms of exhaust temperature, the oil-air compressors exhaust air is reaching up to $70-80^{\circ} \mathrm{C}$. Conversely, the oil-free compressors' exhaust is $15^{\circ} \mathrm{C}$ above the outside temperature that is ranging from -15 to $45^{\circ} \mathrm{C}$ in Ankara conditions. It is possible to utilize the waste heat directly or indirectly with the processes mentioned above. In case of direct applications, the exhaust air can be used for space heating by using an air-to-air heat exchanger. In indirect applications, hot water production can be achieved by using heat pumps.

With this approach, Emergency Waiting Room heating during winter mode is to be achieved and hot tap water to Block $\mathrm{A}$ is to be supplied in summer mode from air-to-water heat pumps. Two air-to-water heat pumps with a capacity of $32 \mathrm{~kW}$ in total are used in this application (Fig. 2).

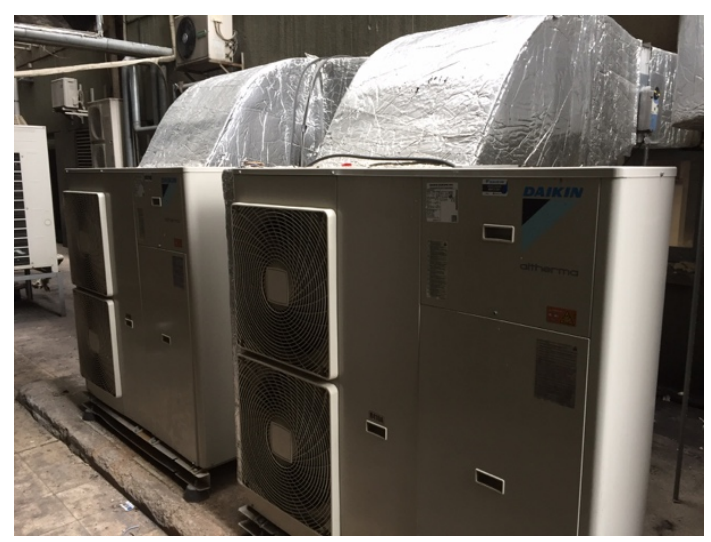

Fig. 2. Air-to-Water Heat Pumps (per unit $16 \mathrm{~kW}$ ) of the facility. 


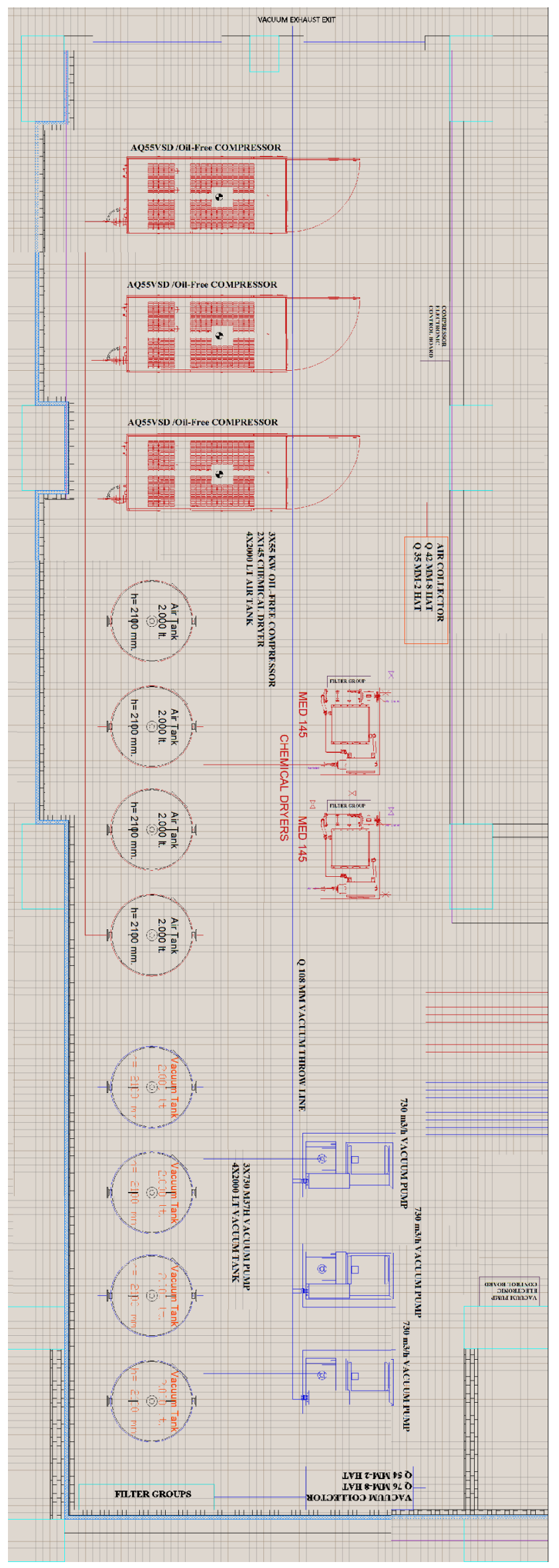

Fig. 3. Medical air plant layout.
The exhaust air of compressors is sent to the heat pumps through fan-duct system, and exhausted to the outside the facility after utilizing the waste heat. Compressor fresh air is delivered with a fan-duct system that is directed towards the suction of the compressors. In this application, the working fluid of the heat pump is R410A and the COP value is 4.12 during the heating process according to the nameplate.

Hot tap water is continuously needed in a hospital during the entire year. The proposed system has an automation to control two different purposes for summer and winter. Through this application, during summer times, Block A's hot tap water is being provided by the heating system and excess water is being loaded into the double coil hot water storage tank for a later use and emergency. During the winter times when the plant works for space heating purposes, this line will be deactivated. An electric heater will be used to heat the boiler water up to $74^{\circ} \mathrm{C}$ once in each week to prevent Legionella bacteria to be formed in water. The hot water storage tank and electric heater for Legionella protection is shown in Fig.4. Plant layout consisting plant equipment connections is shown in Fig. 5.

Before the heat pump implementation, electrical heaters were heating the Emergency Waiting Room. The usage of electrical heaters was resulting with thermal discomfort and leading the place to be misused. With the water circulated through the heat pumps, six radiators located in front of the windows are operating for heating purposes instead of electrical heaters. Consequently, the required warm air for appropriate air conditioning in the emergency waiting room is easily provided to obtain a comfortable space to be used. Fig. 6 shows the thermal images of the radiators in use.

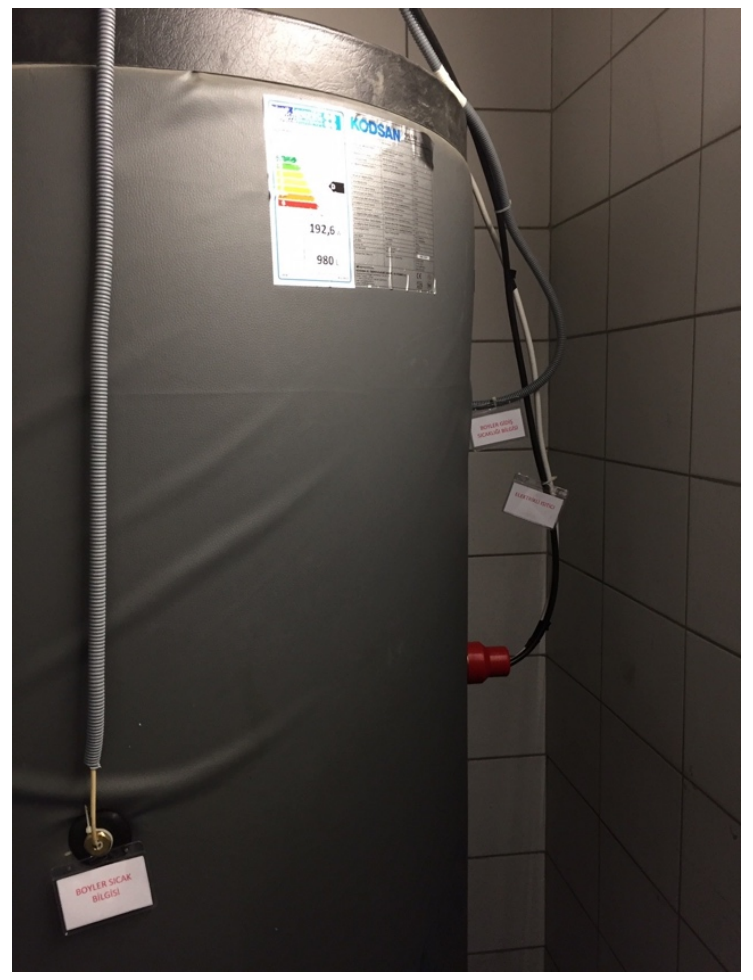


Fig. 4. Hot water storage tank of the facility with electrical heater to prevent Legionella

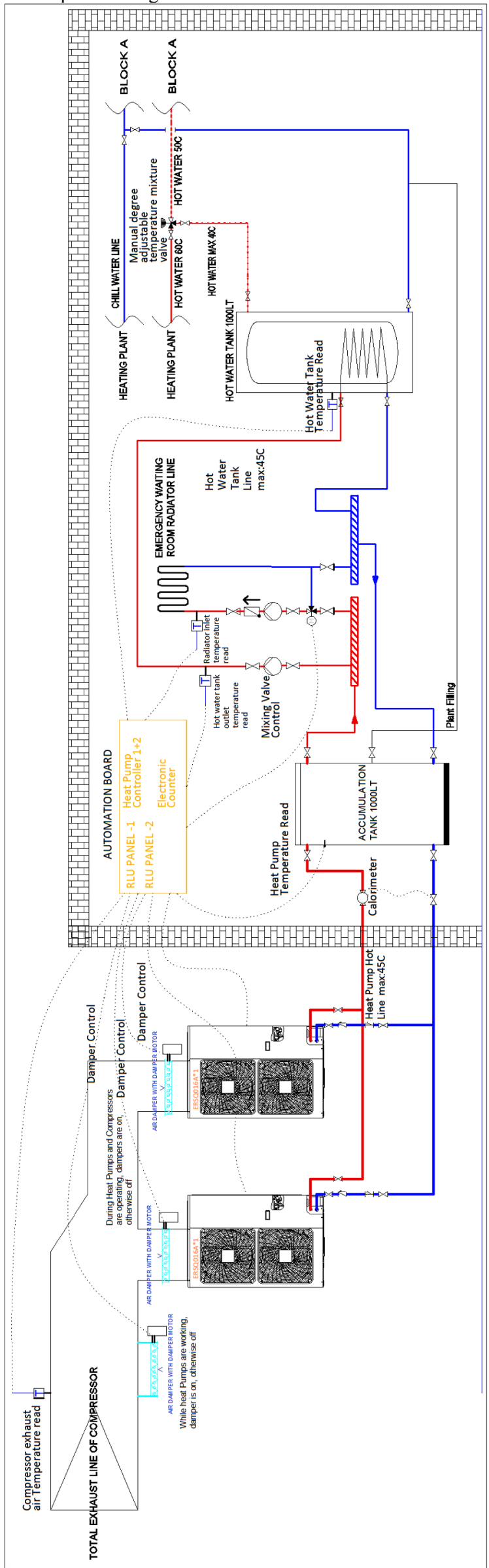

Fig. 5. Heat recovery system model.

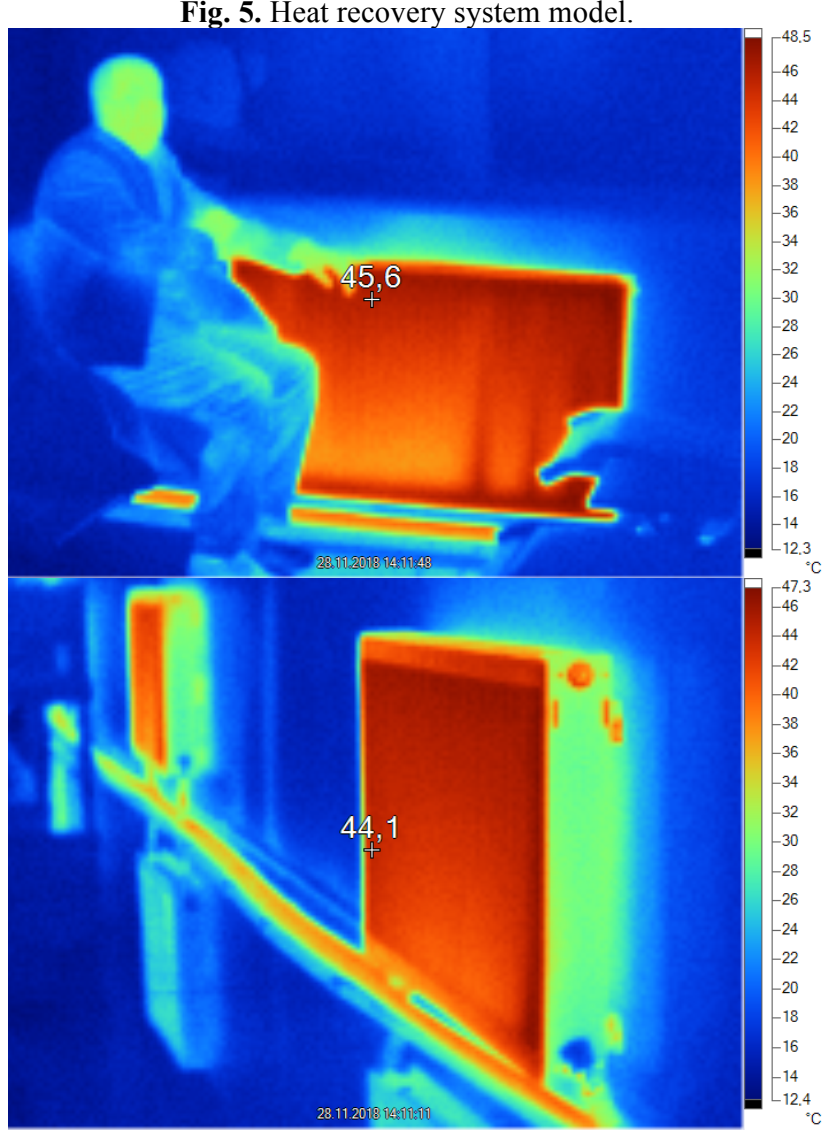

Fig. 6. The thermal images of radiators in the Emergency waiting room.

\section{Conclusions}

Hospitals energy use intensity has to be decreased by considering utilization of waste heat in any kind. For buildings that have such higher EUI (Energy Use Intensity) values, it is extremely important to obtain much higher efficiency values and decreasing the EUI that will lead to a profitable facility heating system and a much sustainable plant. For this purpose, oil-free compressors' with air-to-water heat pumps using the waste heat to obtain heating and hot tap water is achieved.

Hospital has been running a new energy management policy since 2015 to decrease its energy consumption. The energy consumption has decreased due to the new policy (Fig.7). The medical air and vacuum plant is constructed in 2017 and started operating by the start of the year 2018 . Energy consumption of the hospital decreased in 2018 from 3574.92 TOE (Tonne of oil equivalent) to 3460.60 TOE with this renewal project. Parallel to this, consumption by electricity has decreased from $21,878,175 \mathrm{kWh}$ to $20,903,346 \mathrm{kWh}$, from the year 2017 to 2018, respectively. This is an equivalent of 974811 kWh electricity, i.e. 83.818 TOE. 


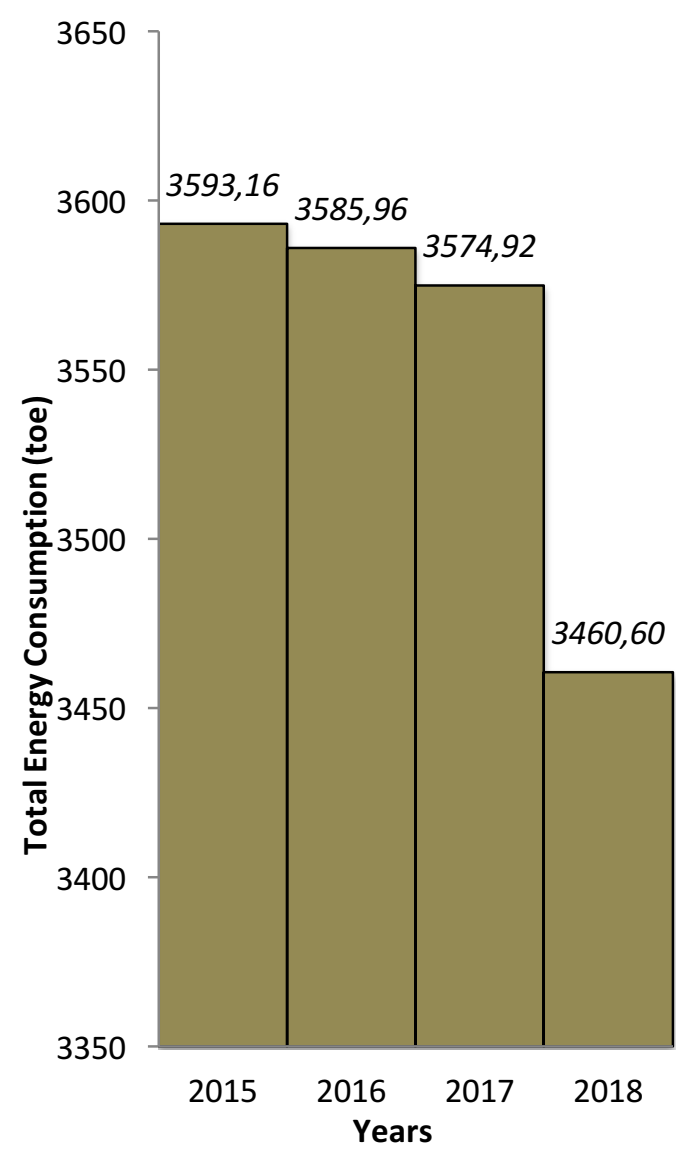

Fig. 7. Total energy consumption by year.

According to the results, in winter mode (space heating), the occupants stated their satisfaction with this application which gives a PMV value +1 . Before the application the space was not in condition to be used, which coinciding with -3 PMV value, obtained from occupant surveys. The analysis showed that the payback time for the system is calculated to be around 2-4 years depending on the heat load. To sum up, air-to-water heat pumps are another reliable, practical, and applicable option to produce hot water from waste heat of the air compressors in a hospital.

\section{References}

1. A. Mazu, Popul. Environ., How Does Population Growth Contribute to Rising Energy Consumption in America, 15, 371-378 (1994)

2. https://www.eia.gov/consumption/commercial/reports/ «U.S. Commercial Building Stock: Results from EIA's 2012 Commercial Buildings Energy Consumption Survey (CBECS) »

3. https://www.eia.gov/consumption/commercial/data/2003/ pdf/e03.pdf « Energy Information Administration, 2003 Commercial Buildings Energy Consumption Survey: Energy End-Use Consumption Tables »

4. http://oee.nrcan.gc.ca/publications/statistics/cices06/pdf/ci ces06.pdf « Natural Resources Canada, Commercial and Institutional Consumption of Energy Survey Summary Report, June $2007 »$
5. https://ec.europa.eu/energy/en/topics/energy-strategy-andenergy-union «European Union Energy Strategy and Energy Union »

6. https://www.eia.gov/consumption/commercial/reports/201 2/water/ « 2012 Commercial Buildings Energy Consumption Survey: Water Consumption in Large Buildings Summary »

7. https://assets.publishing.service.gov.uk/government/uploa ds/system/uploads/attachment_data/file/453973/non_dom estic_building_services_compliance_guide.pdf « NonDomestic Building Services Compliance Guide, HM government, 2013 Edition for use in England »

8. J. A. Pietsch, ASHRAE Journal, The unitary heat pump industry - 25 years of progress,. Illinois Institute of Technology, 19, 15-18 (1977)

9. J. Bouma, Energy Efficiency in Household Appliances and Lighting, International Heat Pump Status and Policy Review, 156-167 (2001)

10. Y. Nam, R. Ooka, Energ. Buildings, Numerical simulation of ground heat and water transfer for groundwater heat pump system based on real-scale experiment, 41, 69-75 (2010)

11. L. Liu, F. Lin, Y. Jiang, Energy, Application of an Exhaust Heat Recovery System for Domestic Hot Water, 35, 14761481 (2010)

12. A.M. De Pasquale, A. Giostri, M.C. Romano, P. Chiesa, T. Demeco, S. Tani, Energy, District heating by drinking water heat pump: Modelling and energy analysis of a case study in the city of Milan, 118, 246-264 (2017)

13. S. S. Cipolla, M. Maglionico, Energy and Buildings, Heat Recovery from Urban Wastewater: Analysis of the Variability of Flow Rate and Temperature in the Sewer of Bologna, 45, 288-297 (2014) 